\title{
Internationalization of Higher Education : A Case Study of Policy Adjustment Strategy in Malaysia
}

\author{
Zuraidah Zaaba, \\ a doctoral student, JAIST Japan, sponsor: \\ Ministry of Higher Education \& UiTM \\ Malaysia, UiTM Malaysia, Sabah Campus
}

\author{
Farida Ibrahim Ramadan, \\ a doctoral student at JAIST Japan, sponsor: \\ Ministry of Higher Education Egypt, \\ Kafrelsheikh University, Egypt
}

\begin{abstract}
At the beginning of the new millennium, Malaysia aspires to become a regional hub for education. Therefore, there is an adjustment strategy in Malaysian higher education policy. Among other elements are and the liberalization of the higher education sector in 1997, which led to the development of language-in-education policy; and the formation of the Ministry of Higher Education in 2004. This policy encompasses the economic, political and socio-cultural domains. Instead of only analyzing economic, political and socio-cultural viewpoints, we analyze this policy from the knowledge perspective. We review the literature on the link between knowledge and policy-making. Then, with emphasis on English language usage, we review language policy in general, and in Malaysia. Case study approach is used; because this gives an in-depth understanding of the policy-making process in Malaysia. The Ministry of Higher Education, Malaysia, policy-making process is the case study. Prior to the case study analysis, we also review the general policy-making process in Malaysia. The findings show that first; the Ministry of Higher Education of the Malaysian Federal Government is generally responsible for most of the policy-making process. And second, benchmarking with international best practices is one of the bases for the development of higher education policy in Malaysia.
\end{abstract}

\section{Introduction}

Beginning in the 1990s, Malaysia's leaders embraced globalization as a force that would allow Malaysia to be integrated into the rest of the world and boost its national economy [5]. This idea was

\author{
Haijon Gunggut,
UiTM Malaysia, Sabah Campus \\ Haijon Gunggut,
UiTM Malaysia, Sabah Campus \\ Chuah Bee Leng, \\ Ministry of Higher Education, Malaysia \\ Katsuhiro Umemoto, \\ Graduate School of Knowledge Science, \\ JAIST Japan
}

translated in 1992 as the Wawasan 2020 or 2020 Vision. The vision states Malaysia's intention to become a developed country by the year 2020 .

\section{Wawasan 2020}

The former Prime Minister of Malaysia, Mahathir bin Mohamad (term of office 1981-2003) introduced Wawaan 2020 in 1991during the presentation of the sixth Malaysian plan. Wawasan 2020 is for Malaysia to become a self-sufficient industrialized nation by the year 2020. This vision encompasses all aspects of life, including economic prosperity, social wellbeing, world-class education, political stability and simultaneously psychological balance. This is summed up into nine challenges. The challenges are [18]:

- Challenge 1: Establishing a united Malaysian nation made up of one Malaysian Race

- Challenge 2: Creating a psychologically liberated, secure and developed Malaysian society.

- Challenge 3: Fostering and developing a mature democratic society.

- Challenge 4: Establishing a fully moral and ethical society.

- Challenge 5: Establishing a matured liberal and tolerant society.

- Challenge 6: Establishing a scientific and progressive society.

- Challenge 7: Establishing a fully caring society.

- Challenge 8: Ensuring an economically just society, in which there is a fair and equitable distribution of the wealth of the nation. 
- Challenge 9: Establishing a prosperous society with an economy that is fully competitive, dynamic, robust and resilient.

The sixth challenge outline in the vision clearly emphasizes the importance of the development of science and technology in a society. The sixth challenge is used to justify the usage of English in higher education institutions, especially in public higher education institutions.

\subsection{The redevelopment of English language in Malaysia}

In the following year, 1993, the former Prime Minister of Malaysia, Mahathir bin Mohamad publicly announced the implementation of English as a medium of instruction for science and technology courses in public higher education institutions. This was the first adjustment strategy for higher education policy. However, the announcement did not amend the Federal Constitution that stated the national and official language is still Malay or Bahasa Malaysia. The Federal Constitution is the superior law in Malaysia. It is under the jurisdiction of the Federal government, the highest level of government in Malaysia.

Historically, the direction of language policy after independence was to instill nationalism and patriotism sentiments. The new independent government was predominantly ruled by Malay leaders, even though the ruling party was an alliance of three major parties from different ethnic groups. Malay language or Bahasa Malaysia or Bahasa Melayu is the national and official language. These terms are used interchangeably. Malay language is the best choice because Malays are the majority in Malaysia, and also because of its role as a lingua franca, its position as the main interethnic communication tool before and after independence. Its possession of high literature, and its previous use as a language of diplomacy and administration in the Malay archipelago. To ensure that the Malay language was widely accepted, it was mandated for a wide range of activities, including media, government and most importantly, education.

In the1980s and early 1990s, there were few public higher education institutions. A policy of affirmative action introduced in 1970, stated the special privileges for Malays and indigenous groups in all sectors in Malaysia. One of the sectors is education. The enrollment priority in public higher education institutions is for Malays and indigenous people. This policy was introduced beginning in 1970 because the Malays and indigenous people were at a competitive disadvantage in the economic sector since independence. This policy has forced the other ethnic groups (i.e. Chinese and Indian) to go abroad to pursue higher education.

In order to accommodate Malaysia's uniquely diverse culture and multi-ethnicity, as well as being a multi-religious society, after the 1993 announcement, the former Prime Minister, Mahathir bin Mohamad redefined the term 'nationalist' to state the rationale of this implementation. He redefined the term nationalist as:

"True nationalism means doing everything possible for the country, even if it means learning the English language" [3].

Tsui and Tollefson [17] believe that the former Prime Minister's redefinition of nationalist is in the context of language competence, in which learning English is seen as a patriotic act.

However, sending students to study overseas is not cost effective after the 1990s due to the economic crisis. In 1997, the Asian economic crisis hit the country. To study abroad was costly. In addition, public universities could not provide placement for all qualified local students. The only solution was to adjust the higher education policy from a conversational to liberalize higher education sector. The approaches are, by expanding private higher education institutions and allowing foreign educational institutions to set up joint-ventures, twinning programmes and branch campuses in Malaysia [8], and by establishing more public higher education institutions.

The increase in the number of higher education institutions within the country offered placement not only to local students, but also to international students. The liberalization of the higher education sector is not only for Malaysians to continue their tertiary education amid economic crisis but also for Malaysia to become a regional educational hub. This liberalization aims to fulfill the ninth challenge in 'Wawasan 2020'.

\section{Ministry of Higher Education Malaysia}

The next adjustment strategy for Higher education policy is the establishment of Ministry of Higher Education on the $27^{\text {th }}$ of March 2004. This ministry is one of the ministries in the Federal Government. The Ministry of Higher Education's vision is to make Malaysia a centre of educational excellence, and to internationalize Malaysian education, especially in the higher education sector. Therefore, the Ministry of Higher Education's mission is to create a higher education environment that will enhance the development of academic and institutional excellence. This environment will enable the development of a superior center of knowledge, and generate individuals who are able to serve not only the needs of the country, but also 
globally. In summary, the mission response to the needs:

- To formulate a strategic and systematic plan for higher education;

- To reinforce the management system of higher education;

- To increase capacity level, accessibility and participation in the higher education sector;

- To enhance the quality of higher education in order to be at par with international standards; and

- To internationalize the Malaysian higher education sector.

The departments and agencies under the Ministry of Higher Education are Department of Higher Education, Department of Polytechnic Management and Department of Community College Management. The agencies are Malaysian Quality Assurance, National Higher Education Fund Corporatio and Yayasan Tunku Abdul Rahman. Public and private higher education institutions are also under the jurisdiction of the ministry.

The Department of Higher Education has two sectors, they are the Public Higher Education Management Sector's jurisdiction is over public higher education institutions, and the Private Higher Education Management Sector's jurisdiction is over private higher education institutions.

The Department of Higher Education and its divisions are responsible for the overall management of higher education. However, any policy-making processes related to higher education will usually involve all departments, divisions, sectors in Ministry of Higher Education; and other stakeholders such as relevant agencies, federal ministries, and industry. The federal ministries for example are Ministry of Education and Ministry of Human Resource; the stakeholders include the Human Rights Commission of Malaysia (SUHAKAM). The industry representative is the Federation of Malaysian Manufacturers (FMM) and Malaysian Employment Federation (MEF).

The Ministry of Higher Education's aspiration to internationalize higher education is not without challenges, especially when faced with the need to continue to uphold the Malaysian Federal Constitution, that states that Malay or Bahasa Malaysia is the national and official language in the country, since the national language is a symbol of nationalism for Malaysia, which gained independence from the U.K. [16][10].

\section{Knowledge and the policy-making process}

Policy is defined by Anderson as a purposive course of action by an individual or individuals when dealing with public issues [7]. For Ranney, policy is a selected line of action or declared intent, while Dye defined it as what governments do, why they do it and what difference it makes [7]. Birkland [2] defined policy as a statement by government of its intention to do something in an area such as law, regulation, ruling, decision and order respectively, or a combination of these. Based on these definitions, we define policy as the intention, purposive course of action and actions using legal tools and mechanisms by legal bodies mostly for public concern

The focus of our research is public policy. Public policy is a process or series, or pattern of governmental activities or decisions designed to rectify some societal problem, either real or imagined. It is a form implemented and evaluated by authorities in a political system [7]. The types of public policies are liberal, conservative, substantive procedural, material, symbolic, collective and private.

As for knowledge, it is about belief, commitment and action. It is a function of a particular stance, perspective or intention. Knowledge is comprised of tacit and explicit; formal and informal [9]. These statements reflect the complexity of knowledge.

\subsection{The management of knowledge in the policy-making process}

Japanese scholars, especially Nonaka and Takeuchi, view knowledge as tacit and explicit [9]. Some western philosophers, namely Drucker, Toffler and Quinn, mention knowledge as the main source of development, and the knowledge society can bring development to a country.

A major difference between Japanese and Westerners is that the former greatly emphasize tacit knowledge, whereas the latter greatly emphasize explicit knowledge. Western philosophers view knowledge as explicit-something formal and systematic. It can be articulated, codified and stored. Once consumed, the knowledge is transmitted to others. For Japanese companies, knowledge is both explicit and tacit [9]. Tacit knowledge is difficult to transfer. It is in the mind of the individual that knowledge turns into wisdom, intuition, experience, talent, judgment, and expertise. Therefore the Japanese address the issue of organizational knowledge creation [9].

Recently, scholars believe that the knowledge perspective is influencing all aspects of the policymaking process [11][13]. However, they mainly focus on knowledge utilization from research, and also on the difficulties of knowledge acquisition and sharing during the policy-making process [1].

Knowledge management in the organization focuses on knowledge sharing, acquisition, and utilization. These three processes in knowledge management are the catalysts of knowledge creation [20]. 
Efficient knowledge-sharing management means disseminating and allowing easy access to knowledge for all bodies and individuals in the organization. Conferences, meetings, media announcements and communities of practice are some examples of venues where knowledge can be shared.

Knowledge acquisition means developing and creating intellectual capital, which includes internal and external knowledge, for example insights, skills, experience and relationships. Knowledge utilization occurs when the knowledge is applied [9]. This process is achieved when knowledge is available at the right place and at the right time. The effective and efficient management of knowledge sharing, acquisition and utilization create dynamic, new and innovative knowledge. This can be described as 'knowledge creation [9].

In the management and organization fields, knowledge creation is widely researched. There is little being said explicitly on knowledge creation in the policy-making process in developing [12] and developed countries. In developed countries, knowledge creation is actually highlighted in policy innovation [15] and the evidence and arguments during the policy-making process lead to the identification of problems, creation of ideas, and problems-solving [2]. In developing countries, knowledge in public policy is widely studied in the development domain [1]. All these studies refer to explicit knowledge.

In the developed countries, knowledge creation is implicitly elaborated in Roberts and King [15] policy innovation. It is a departure from existing practices. The evidence and arguments in the policy-making process implicitly describe knowledge creation. Other scholars have stated that knowledge is created by chance, learning or consensus in the policymaking process. Chance is based on policy, problem and politics streams. All streams are mutually exclusive. They develop by their own dynamics and rules. The greatest knowledge creation or policy change occurs when all of the streams are joined. Learning occurs through advocacy coalition that share belief and system. Consensus occurs when elites from the three political cultures find and integrate solution that meets their preferences. The three cultures are the hierarchical collectivism, competitive individualism and egalitarian collectivism.

In developing countries, policy-making activity is often active during crises, either domestic or external. Nevertheless, during both crises and stable situations, policy-making for innovation or change is greatly influenced by the interests and convictions of political entrepreneurs who hold positions in the policy-making system [15]. Hezri [4] studied the sustainability indicator system and policy process in Malaysia and highlighted the constraints on knowledge utilization and learning processes due to meta-policy. This evidently top-down approach, which is still practiced by many developing countries, reflects the interests of the authorities in public policy. In addition, international relations in terms of aid, and political, economic and social influences would also be reflected in the public policies of developing countries.

\section{Language-in-education policy}

In the period after World War II, policy is studied from political, economic and socio-cultural perspectives, and there was a new emergence of international governmental structures and operational rules; English, French and Russian were declared to be the official languages of science information, and only the United States (US) was a major industrial power with its scientific and educational infrastructure completely intact. Most of the colonial countries were ruled by English-speaking countries.

These developments influence the great majority of the world's population at present to continue to choose English as the first or alternative language [6]. The independent developing countries, especially the ex-British colonies, preferred to use English as the main or one of their official languages because of unity and economic development.

Although most educational policies continue to be national or local decisions, language policy making is also internationalized, especially at the end of the colonial period and the beginning of globalization. Globalization has brought about an unprecedented spread of English, and the spread of English has posed a serious challenge to nonEnglish-speaking countries [17]. The challenges are towards sociopolitical, economic and cultural impacts for non-English-speaking countries, most of which are developing countries. For Japan, South Korea, Vietnam and many countries around the world, the foreign presence was both resisted and accommodated in ways that shaped the three countries' language policies. Apart from the step to increase and improved language education as part of broad economic development, English promotion policies have begun to dominate educational language policies in South Korea, Vietnam and many countries in the world [10].

The impact of globalization and the hegemony of English can be seen from the resurgence of the debate on the recognition of English as an official language, and its adoption as the medium of instruction even in countries that are highly protective of their national languages and cultures [17]. In addition:

"The language does not have a will of its own to become dominant, it is the English speakers...... And most important, people who govern a country also 
can instigate the spread of English through policy" [5][20].

The leaders of the developing countries, whose populations are multi-ethnic and multi-lingual, believe that English as the official language during the colonial period did unite the country at that time. Continuation would maintain unity even after independence. In India, Pakistan and Bangladesh after independence, English has retained its status, and has continued to be the medium of instruction for the elite and higher education institutions.

In Malaysia, though Bahasa Malaysia is used for nation-building, the re-adoption of English as the medium of instruction for science and technology courses in tertiary education has been decided.

\section{Language policy in Malaysia}

British involvement in Malayan (Malaysia before independence) education began at the end of the First World War. This began when British administrators needed English-speaking employees to fill positions in the civil service and commercial organizations in Malaya. British funded both English schools and a Malay system of education at the primary level. Initially, English schools had been previously set up by missionaries before British government involvement.

The Malay system of education was compulsory. The support for Malay education was due to the fact that the British felt an obligation towards Malays as sons of the soil or bumiputera. Malays are the people who were the earliest occupants of the land. Later, after Sabah and Sarawak joined Malaya to form Malaysia, the term bumiputera or sons of the soil has been used to encompass Malays, aborigines (an indigenous minority in Malaya) and the indigenous peoples of Sabah and Sarawak. The other vernacular systems of education were the responsibility of their respective immigrant groups, the Chinese and Indians. Later the British provided limited aid in the form of financial grants for these schools.

All the vernacular systems of education were only at the primary level. Only the English system of education continued at the tertiary level. English education was concentrated in urban areas. This gave opportunity mostly to Chinese, a few upper-class Malays and wealthy Indians. Upper-class Malays refers to royals, aristocrats and Malay chieftains. There were English-medium higher education institutions set up in Singapore and Malaya, so English-educated students could either further their studies in one of these institutions, or study at other schools in the British Commonwealth.

Towards the end of British rule in Malaya, there was an initiative to start using only Malay-language for all primary schools. In 1950, the Barnes Committee stated that Malay primary schools should be employed as a tool to build up Malaya nationalism. Barnes report proposed a primary national school with Malay and English language as the medium of instruction. It was hoped as this national schools developed the Chinese and Indian vernacular schools would gradually phased out.

Barnes report failed to gain support from the Indian and Chinese communities. The Chinese and Indian presented a Fenn-Wu report; insisting the continuation of Chinese and Indian medium of instruction. Barnes reports was abandoned and replaced with the Razak report.

After Malaysia gained independence in 1957; there is still national school and national-type school. National school medium of instruction is Malay and national-type school is Mandarin for Chinese and Tamil for Indian vernacular school respectively.

\subsection{The transition period}

Since Malaysia gained independence, the national and official language is Malay, as stated in the Federal Constitution. However, English was allowed to share official language status with Malay for ten years (1957-1967). The transition from English to Malay was slow in the education system. This allowed the continuation of the English system of education, the Malay system of education, the Chinese system of education and the Indian system of education.

As a result, the English-educated students and graduates continued to find employment in the public and private sectors. The government began seriously implementing the transition from English to Malay in the education system in 1970, only after the 1969 election. In the 1969 election, the Alliance of the ruling parties in Peninsular Malaysia consisted of the United Malays National Organization (UMNO), Malaysian Chinese Association (MCA) and Malaysian Indian Congress (MIC) political parties, which lost most of their constituency to Democratic Action Party (DAP). This led to racial riots between the Chinese and Malays.

The transition from English to Malay was gradual at the primary and secondary level; it was completed in 1983 for Peninsular Malaysia and in 1985 for the states of Sabah and Sarawak. At the higher education institutions, the University of Malaya, which was set up during the colonial period, still continues teaching some courses in English especially in science and technology courses; even though courses in social sciences and arts were gradually being taught in Malay language. University of Malaya was the only university in Malaysia in the early days of independence, and this university is still a bilingual public higher education institution in the 1970s.

Therefore, there was a need to set up more public higher education institutions in order for Malay to replace English as the medium of instruction at the 
public higher education institutions by 1983. In 1970, the National University of Malaysia was formed, followed by the University of Technology Malaysia, University of Agriculture Malaysia (currently known as Putra University of Malaysia) and the Science University of Malaysia.

The first three new public higher education institutions used Malay as the medium of instruction, while University of Malaya and Science University of Malaysia largely used English. The reason these two public higher education institutions continued to use English as a medium of instruction was stated in Malaysia's second five-year plan (1970-1975) of National Economic Plan:

"to continue to emphasize English as the language for acquiring and accessing knowledge in science and technology. This acceptance of a foreign language, particularly the English language, was meant to promote the development of the nation via science and technology"[10].

The five year plans continued until 1990. From 1990s onward, the National Economic Plan was replaced with the National Development Plan. National Development Plan still continues the objectives of the National Economic Plan.

\subsection{Globalization impact}

The fact that public higher education institutions continue to use English in science and technology courses, reflects their awareness that it is the fastest way to acquire and transfer knowledge in science and technology. There are few science publications in Malay, but there are many publications in English. There are many experts in science and technology who are proficient in English.

Dewan Bahasa dan Pustaka, a language agency established in 1956 is responsibility for corpus planning. The agency was to develop and enrich the national language [10]. This agency's goal was to ensure that Malay language would develop and be able to cope with the sociological development of Malaysia. And there have been efforts by scholars and Dewan Bahasa dan Pustaka to publish articles and books in scientific Malay, but progress has been slow. Progress cannot keep pace with the ongoing process of development and the rapid expansion of new theories, methodologies, approaches and findings in science and technology. The translation initiative cannot keep pace with the voluminous expansion of scientific writings and new discoveries made by scientists globally. Translated works are outdated by the time they are ready for publication.

The government is aware of the situation, and thus allows the public higher education institutions to continue with English as the medium for science and technology courses. Globalization is a trend in which factors such as economic considerations, the knowledge economy, and science and technology policy outweigh the traditional factors of politics and nationalism in influencing language policy [17]. English is the best medium of instruction because it is widely used in science and technology fields.

In 1993, English was announced to be the language used for science and technology in the public higher education institutions. This announcement does not amend the law related to the official language. Therefore there is a need to have an adjustment strategy for English language could be implemented in the higher education institutions.

To ensure English usage in science and technology course is reinforced in the public higher education institutions; in 1995 Education Act 1995 gives the Minister of Education greate1996, the Higher Education Act of $\mathrm{s}$ power than before in many education matters [19]. In 1996 and the 1996 Private Higher Education Institution Act were introduced. This inevitably encouraged the implementation of English as a medium of instruction for science and technology courses in public higher education institutions. The Higher Education Act of 1996 also requires Malay to be a compulsory subject in private educational institutions, if the medium of instruction is other than the national language.

This reinforcement reflects that decision-making in the Malaysian education system is a highly centralized and bureaucratic top-down system [6]. If this is the case, how do the policy makers share, acquire, utilize and create knowledge in the process of policy-making?

Therefore, this paper is trying to fill in the gap regarding how tacit and explicit knowledge lead to knowledge creation in the various stages of the policy-making process for higher education in Malaysia. This study examines the adjustment strategy focusing on the policy-making process regarding the usage of English as a medium of instruction for teaching science and technology courses in public higher education institutions, to close this gap.

\section{Objectives and methodology}

Previous language-in-education policy literature mainly evolved in the political, socio-cultural, historical, administrative, legislative and economic domains, while in fact, in the policy-making process, knowledge sharing, acquisition, utilization and creation have significant roles in agenda-setting, policy formulation, policy implementation and evaluation. Therefore, this paper analyzes the internationalization of higher education, emphasizing language-in-education policy from the knowledge perspective. The focus is on English language use as a medium of instruction for science and technology courses in public higher education institutions in 
Malaysia. There are two areas we have concentrated on, they are:

- To analyze the process of developing an adjustment strategy of the policy

- To analyze knowledge in the policy-making process

Case study approach is used, since this gives an in-depth understanding of the policy adjustment strategy process in Malaysia. Primary data was collected through interviews with officials from the Ministry of Higher Education, Malaysia. Secondary data, for example government documents, have been collected to analyze the policy-making process in Malaysia, and a literature review includes the knowledge link to the policy process and languagein-education policy in general, and in Malaysia.

\section{Discussion}

\subsection{Policy-making process in Malaysia}

There are three levels of government in Malaysia (Figure 1). Federal government has jurisdiction over the Federal Constitution. State government has jurisdiction over the state legislation, and Local government has jurisdiction over bylaws.

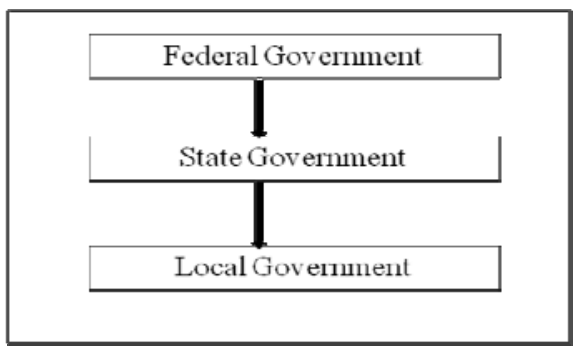

Figure 1. The Government System in Malaysia [20]

A new or adjusted policy is initiated by the responsible ministry. The process begins with agenda-setting and policy formulation simultaneously. Issues are selected at the ministry level. Investigation in the form of research and other means would be the next step. The report would be presented at the ministry level for review. Once deliberated, a Cabinet paper containing the rationale, need and objective for a policy is compiled by the responsible ministry. This paper is circulated to all related ministries for comments, and the feedback is incorporated into the Cabinet paper prepared by the responsible ministry. The policy would be reviewed again at the responsible ministry before deliberation. This policy is submitted to the Cabinet Division (a division of the Prime Minister's Department, which functions as a secretariat to the Cabinet).

The next stage is the debates and deliberation at the Cabinet meeting. The Cabinet Division prepares copies for circulation at the Cabinet meeting (consisting of all the ministers in the Federal government with the authority to consider and endorse government policies). At the Cabinet level the policy would be debated and if it needs review, it would be sent back to the responsible ministry for another review. This process would continue until the Cabinet deliberates the policy. If there is a new act/law or an amendment in the legislation, the responsible minister would bring up the policy in the Parliament. Parliament is the highest legislation body in Malaysia. If the parliament requests amendment of the policy, the respective minister would again review the policy. This process would continue until Parliament approves the policy. Once the policy is approved, a public acknowledgment of the new policy would be made, and the public is entitled to make comments. If the new policy does not amend or create legislation, the respective minister or the Prime Minister or the Deputy Prime Minister would announce the policy.

The final stage is policy presentation and exchange of information between the government and the public is the responsibility of the Department of Information. The Department of Information also acquires feedback from the public and persuades the public to accept and participate in the government policies. The communication is in the form of seminars, documentaries, dialogue sessions, lectures and film shows. The mass media is utilized as a means of publicity, announcement, awareness and providing information.

The Malaysian Civil Service Link provides a single main gateway linking to all government websites, and providing access to government information and various government policies. The Implementation and Coordination Unit of the Prime Minister's department monitors the implementation of program components. Policy evaluation is undertaken by the respective ministries, the implementers, and the Macro and Evaluation Division of the Economic Planning Unit of the Prime Minister's Department. The responsible ministry and the implementing institutions evaluate the outcome of the policy; the Economic Planning Unit evaluates the impact of government policy on the quality of life and the country as the whole.

\subsection{Higher education policy adjustment strategy}

The Ministry of Education was the responsible ministry to set up the policy of Higher Education until 2004. After the announcement of the teaching of science and technology course in English in1993, the ministry has initiated and adjusted legislation and policies that indirectly reinforced the implementation of English language usage in public higher education institutions. The 1998 Corporatization of public higher education institutions was done to enable the 
public higher education institutions to be competitive with the private higher education institutions, especially after the liberalization of higher education in Malaysia.

However, all this legislation only has jurisdiction within the boundary of the tertiary level. The primary and secondary levels of education were not affected. The national school leavers, the main group for higher education, are Malay-educated; this created an obstacle for them while studying at the tertiary level. In 2003, teaching science and mathematics in English was introduced at the primary and secondary levels for both national and national-type schools.

The society responded both positively and negatively. The urban Malays and the Indians applauded the move. The nationalist Malays feel a threat to their sense of patriotism, and the Chinese feel a threat to their effective education system.

The conflict regarding the language-in-education policy eventually led to the set up of the Ministry of Higher Education in 2004.

\subsection{Ministry of Higher Education policy- making process}

Education and language are under the Federal Constitution; therefore, the Ministry of Higher Education is accountable for agenda-setting and policy formulation or adjustment of language education policy at higher education institutions (Figure 2).

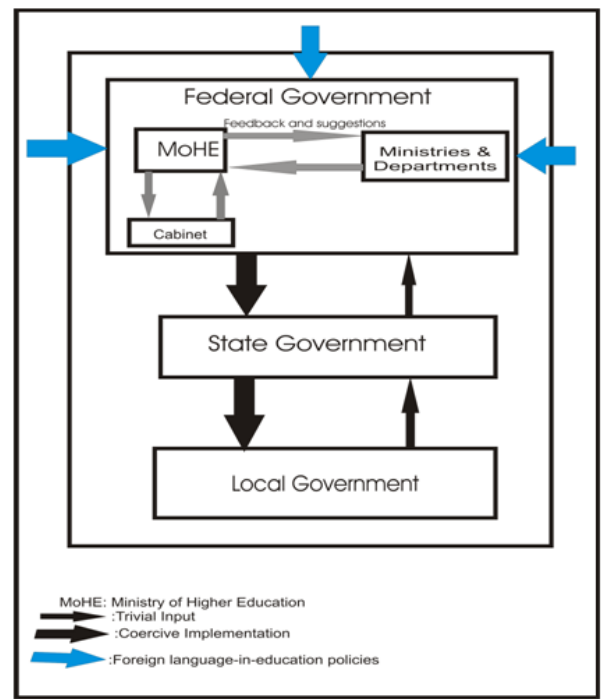

Figure 2. A summary of higher education policymaking process concentration

Based on the data collection and government documents, we provide a comprehensive description of the policy-making process of the Ministry of Higher Education.

The agenda-setting and policy formulation or adjustment in the Ministry of Higher Education begins with the weekly management meetings of the
Heads of Departments and the Policy Review Committee on an alternate basis. The committees' members are the same. They comprise five departments:

- Development Department,

- Management Department,

- Higher Education Department

- Polytechnic Department

- Community College Education Department.

The divisions of all the departments also attended the meetings with the Malaysian Quality Assurance Agency, the National Higher Education Fund Corporation and Yayasan Tunku Abdul Rahman. Both weekly management meetings are chaired by the Secretary General of the Ministry of Higher Education.

Issues related to higher education will be discussed in the both management meetings in order to gather feedback, which would in turn be used as input. At times issues can also be raised by the members of the meeting at the Heads of Departments and Policy Review Committee meetings. Often times, the feedback channels can also come from issues frequently raised in the Parliament or from the media. There are also other feedback channels, for example Non-Governmental Organization (NGO), Integrated Complaint Management System (ICMS), Prime Minister's Blog and Public Complaints Bureau of the Prime Minister's Department of Malaysia.

In each instance, Ministry of Higher Education will identify relevant issues related to higher education to be deliberated upon, to see if an issue warrants further study. The vision to make Malaysian higher education a centre of educational excellence, and to internationalize Malaysian higher education, is the focal point for the selection of issues.

The Heads of Departments and Policy Review Committee would also identify other relevant issues that may need further review. The other relevant issues will be related to intellectual capital, economic issues and socio-cultural issues. As with the issue of language-in-education in public higher education institutions, this issue is usually combined with other issues related to and with higher education that could lead to the internationalization of higher education in Malaysia. In 2010, the Ministry of Higher Education assigned a study related to the usage of language in public higher education institutions, but this is still in the early stage yet.

Once these issues are deliberated, agenda is set. These issues will usually be forwarded to the Planning and Research Division for further action. Generally, further studies will be conducted on pertinent issues. There are three types of studies:

- Feasibility study

- Development study 
- Impact study

These will usually involve the engagement of expertise from higher education, or other nonacademic institutions. The selection of expertise will be based on the higher education or non-academic institutions' niche areas. The experts will be given a frame of reference or a guideline, and a budget for them to conduct the research. On issues related to language-in-education policy, experts are:

- National University of Malaysia, Faculty of Social Sciences and Humanities

- Mara University Technology of Malaysia, Academy of Language Studies

- Science University of Malaysia, School of Languages, Literacies and Translation

- University of Malaya, Faculty of Languages and Linguistics

- Putra University of Malaysia, Faculty of Modern Languages and Communication

- North University of Malaysia, Language Center. The research findings will then be presented in the Technical Committee and later, to the Steering Committee. The Technical Committee includes:

- Under Secretary of Planning and Research Division, the chairman

- Senior Assistant Secretary, Chief Macro Section for Human Resource Development

- $\quad$ Principal Assistant Secretary of Planning and Research Division

- $\quad$ Other members from the Ministry

The Steering Committee includes:

- Secretary General of the Ministry of Higher Education, the Chairman

- Internal and external members, expertise and authority relevant to the researched issue

Issue related to language-in-education policy, the relevant ministries for example will be Ministry of Education and Ministry of Human Resource.

Usually, there will be several presentations, where a topic will be deliberated upon until both committees are satisfied with the report. There are three levels of presentation:

- Inception report-this is a presentation of a proposal from the experts who form a consultant team in the first month

- Intermediate report

- Final report

If the research is conducted for a six months period, the report presentations will be in the second, fourth, fifth and sixth month. The approved final report from both committees will then be disseminated among the key players and relevant stakeholders for feedback. There are also cases that a final report failed to get approval from the Technical and Steering Committee despite undergoing these levels of presentation.

The next step will involve processes and activities related to and geared towards the formulation or adjustment of policy. This will come under the purview of the Planning and Research Division. The formulation will be based on the research findings as input, and explores avenues and recommendations that are deemed pragmatic and implementable, and the vision and mission of higher education. This formulation is usually a long and tedious process that involves relevant divisions, departments, other ministries, agencies and stakeholders such as relevant industries for feedback.

The final stage of the formulation or adjustment policy begins in the Planning and Research Division or the Department of Higher Education. This depends on which division or department is given the responsibility. The recommendation from the final report merged with the current higher education policies and other relevant government policies will be translated into drafted policy. This drafted policy will be submitted to other relevant ministries and stakeholders. The ministries will always include the Ministry of Education and Ministry of Human Resources and other relevant ministries. The stakeholders will be in industry, for example Federation of Malaysian Manufacturers.

Once feedback is received, it will be further reviewed, assessed and deliberated upon in the Policy Review Committee, before it is deemed satisfactory to be sent to the Policy and International Division for procedural purposes. The Policy and International Division will submit a policy proposal to the Cabinet for debate. Once the drafted policy is debated in the Cabinet, the Cabinet would decide either to approve it or request changes.

Any implementation related to public or private higher education institutions comes under the responsibility of the Department of Higher Education. For action plans, like the language-ineducation policy involving the usage of English as a medium of instruction for science and technology courses for internationalization of Malaysian higher education, several approaches will have to be considered. The approaches include the setting up of private higher education institutions, of which the medium of instruction is English, which would attract more international students to study in Malaysia. Public higher education institutions with the medium of instruction for science and technology courses in English, and liberalization of higher education, would allow public higher education institutions' enrollment to be expanded to international students as well.

\section{Analysis}

\subsection{Knowledge perspective analysis}

From the knowledge perspective, all the knowledge input, either tacit or explicit, in the policy-making process for higher education is taking place in the 
Federal Government (Figure 2). Although there is input from society, the selection of issues only occurs at the Ministry of Higher Education, Federal Government level.

Knowledge feedback begins during knowledge sharing and acquisition in the Head of Departments and Policy Review Committee meetings. Issues would be selected and filtered to consider only crucial issues, especially to fulfill the vision and mission of higher education. This is the stage at which knowledge selection and filtration begin. At this stage the tacit knowledge begins merging with selective explicit knowledge. One of the crucial issues is the usage of English for science and technology courses in public higher education institutions. This issue of language-in-education policy has indirectly led to internationalization of higher education in Malaysia.

The selective issues then would be investigated through research; this is when knowledge utilization concerned with evidence or fact-finding and problems are important for policy formulation or adjustment. All the research so far would also include external knowledge i.e. benchmarking for international best practices [14] that would be used for recommendations. At the research level, knowledge creation emerges during the recommendation stage, which is to be partly used at the implementation stage. This is again the stage at which tacit knowledge becomes explicit, and merges with the selected explicit knowledge.

Once research is completed and presented in committees i.e. initially the Technical and Steering Committee and later to the Head of Departments and Policy Review Committee, knowledge filtration continues and knowledge prioritization begins. This is the stage at which again tacit knowledge would emerge as explicit knowledge.

For policy formulation or adjustment, this is the stage where the Planning and Research Division or Department of Higher Education begins to formulate or adjust policies and create a plan of action. Knowledge politics, knowledge culture, knowledge economy, knowledge research and external knowledge are utilized at this stage. The draft would then be sent to the relevant federal ministries and stakeholders for knowledge feedback.

The final drafted policy then would be submitted to Policy and International Division for procedural purposes and proper documentation. Policy and International Division is responsible to ensure that the final draft of the policy can be submitted and debated in the Cabinet. The Cabinet either approves the policy, or requests the drafted policy to be amended. Knowledge feedback, knowledge selection, knowledge filtration and knowledge prioritization would continue during the Cabinet sessions to approve the policy, and during the implementation strategy. The implementation strategy can be a plan of action by the responsible department in the Ministry of Higher Education, and with the partnership of various stakeholders.

\subsection{Overall analysis}

The language-in-education policy in Malaysia since independence is still influenced by British colonial education. There are still national schools and national-type schools. English serves as the second language for all the schools. At the higher education level, English continues to be the medium of instruction, especially for science and technology courses, along with Malay.

In 1992, Wawasan 2020 was launched with the intention that by the year 2020 Malaysia will become a developed country. This coincides with the globalization era. For Malaysia to be assimilated in globalization and to achieve Wawasan 2020, knowledge needs to be acquired efficiently and effectively. In 1993 the previous Prime Minister announced teaching science and technology in English for public higher education institutions. However, there is a challenge; Malay is still the national and official language. In 1995, the Education Act expanded the authority of the Minister of Education. In 1996, Higher Education Act and Private Higher Education Act were introduced. The former implicitly allows teaching science and technology in English; the later explicitly legalizes English as a medium of instruction for private higher education institutions.

In 1997 Malaysia was affected by the Asian economic crisis, inevitably liberalization of higher education is feasible in Malaysia. Teaching science and technology in English for higher education is part of the liberalization of Malaysian higher education. This implementation is possible because the nature of policy-making in Malaysia is top-down approach. However, there is a setback.

The problem with Malaysia is that since policy making is a top-down process, people's involvement at the policy formulation level is minimal. Only after a policy is passed real engagement of the mass public occurs. This is a little too late. Thus sharing is delayed. This probably explains why many policies in Malaysia are very unstable or consistently inconsistence. We agree, there is liberalization internationally, that is, the influence of globalization process reflected in the importance of English language in the education sector, but domestic liberalization in the context of knowledge creation/sharing in policy are very limited.

\section{Conclusion}

The Ministry of Higher Education is the only 
federal ministry responsible for agenda-setting and policy formulation or adjustment tasks. This restricts policy adjustment strategy of the language-ineducation policy, as well as internationalization of higher education policy, to the involvement of ministries, leaders, politicians and economists at the federal government level only. The other setback is that language and education are listed in the Federal Constitution, i.e. they are subject to federal government jurisdiction.

It is intriguing even at the start of the new millennium, in which knowledge is greatly emphasized for a country's development and survival in the globalization era; that knowledge sharing, acquisition, utilization that lead to knowledge creation in Malaysia are still concentrated at one level of the government due to jurisdiction restrictions. This means that knowledge sharing, acquisition and utilization have not yet been truly liberalized in Malaysia. This might impose some constraints on the internationalization of higher education in Malaysia.

The limitation of our approach is we focus on the institutional structure and the processes of policymaking. This would ignore informal process such as the role of influential personalities and changes in government leadership.

Our future research will be to expand our description of the policy-making process in the Ministry of Higher Education to a theoretical model.

\section{Acknowledgements}

We would like to thank Miss Mooradian from Global Communication Center of JAIST Japan for her helpful comments. Thank you to Ministry of Higher Education Malaysia (MOHE) and Universiti Teknologi Mara (UiTM) Malaysia for sponsorship. Finally, thanks to Planning and Research Division of MOHE for their support during our research.

\section{References}

[1] Ashford, L. S., Smith, R. R., D. S., Roger-Mark, Fikree, F. F. and Yinger, N.V. (2006) 'Creating Windows of Opportunity for Policy Change: Incorporating Evidence into Decentralized Planning in Kenya', Bulletin of the World Health Organization 84 (8), pp. 669-672.

[2] Birkland, T.A. (2011) An Introduction to The Policy Process: Theories, Concepts, and Models of Public PolicyMaking ( $\left.3^{\text {rd }} E d\right)$, M.E. Sharpe: New York.

[3] Gill, S.K. (2002) International Communication: English Language Challenges for Malaysia, Universiti Putra Malaysia Press: Serdang, Selangor.

[4] Hezri, A.A. (2004) 'Sustainability Indicator System and Policy Process in Malaysia: A Framework for
Utilization and Learning', Journal of Environmental Management.73, pp. 357-371.

[5] Kaplan, R.B. (2001) 'English - the Accidental Language of Science?', in The Dominance of English as a Language of Science: Effects on Other Languages and Language Communities, Ammon, U., Ed. Mouton de Gruyter: Berlin, pp. 3-26.

[6] Kaplan, R.B. and Baldauf Jr, R. B. (1997) Language Planning from Practice to Theory, Multilingual Matters: Clevedon.

[7] Lester, J. P. and Stewart, J. (2000) Public Policy: An Evolutionary Approach, Wadsworth: Belmont.

[8] Malaysia as an Education Hub; http://www.angelfire.com/mi/gempak/msc61.html February 2011).

[9] Nonaka, I. and H. Takeuchi, H. (1995) The KnowledgeCreating Company. Oxford: New York.

[10] Omar, A. H. (1979) Language Planning for Unity and Efficiency: A Study of the Language Status and Corpus Planning of Malaysia, Penerbit Universiti Malaya: Kuala Lumpur.

[11] Pollard, A. and Court, J. (2005, July) 'How Civil Society Organizations Use Evidence to Influence Policy Processes: A Literature Review', Working Paper 249, Overseas Development Institute, London; http://www.odi.org.uk ( 1 February 2010).

[12] Porter, R.W. and Hicks, I. (1995) 'Knowledge Utilization and the Process of Policy Formation', SARA Project is operated by the Academy for Educational Development as a component of the HRAA Project of the Africa Bureau, U.S. Agency for International Development (AFR/SD/HRD);

http://sara.aed.org/publications/cross_cutting/knowledge_u tilization/html/utilization.htm (10 December 2009).

[13] Radaelli, C.M.(1995) 'The Role of Knowledge in the Policy Process', Journal of European Public Policy 2 (2), pp.159-183.

[14] Report by the Committee to Study, Review and Make Recommendations Concerning the Development and Direction of Higher Education in Malaysia, (2006) UPENA: Shah Alam.

[15] Roberts, N.C. and King, P.J. (1996) Transforming Public Policy: Dynamics of Policy Entrepreneurship and Innovation, Jossey-Bass: San Francisco.

[16] Tsui, A.B.M. and Tollefson, J.W. (2004) 'The Centrality of Medium-of-Instruction Policy in Sociopolitical Processes', in Medium of Instruction Policies - Which Agenda? Whose Agenda?, Tollefson, J.W. and Tsui, A.B.M. Eds. Lawrence Erlbaum Associates: New Jersey, pp.1-18.

[17] Tsui, A.B.M. and Tollefson, J.W. (2007) 'Language Policy and the Construction of National Identity', in 
Language Policy, Culture and Identity in Asian Contexts, Tsui, A.B.M. and Tollefson, J.W. Eds. Lawrence Erlbaum Associates: New Jersey, pp.1-21.

[18] Wawasan 2020; http://www.wawasan2020.com/ (19 May 2010)

[19] Wong, R. Y. L. and James, J. E. (2000) 'Malaysia’, in Language Policies and Language Education, Kam, H. W. and Wong, R. Y. L. Eds. Times Academic Press: 1 New Industrial Road, Singapore, pp. 209-240.

[20] Zaaba, Z., Ramadan, F. I. M., Aning, I. N. A., Gunggut, H. and Umemoto, K.(2011) 'Language-inEducation Policy in Malaysia: A Study of Policy Adjustment Strategy in Malaysia', International Journal of Education and Information Technologies 2 (5),pp.157165 ;

http://www.naun.org/journals/educationinformation/(13 (1 January 2011). 